Verhaak, P.F.M., Koopmans, B., Ngo, D., Faber, E. Eigen bijdrage in de GGZ stoot niet de mensen met lichtere problematiek maar de minder draagkrachtigen af. TSG: Tijdschrift voo Gezondheidswetenschappen: 2013, 91(5), 270-275

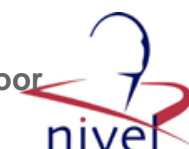

\begin{tabular}{|l|l|}
\hline $\begin{array}{l}\text { Postprint } \\
\text { Version }\end{array}$ & 1.0 \\
\hline Journal website & http://vb23.bsl.nl/frontend/login.asp?page=1388-7491l09014f3c802debb7.html \\
\hline Pubmed link & \\
\hline DOI & \\
\hline
\end{tabular}

This is a NIVEL certified Post Print, more info at http://www.nivel.eu

\title{
Eigen bijdrage in de GGZ stoot niet de mensen met lichtere problematiek maar de minder draagkrachtigen af
}

\author{
Peter FM VerhaAK, ${ }^{1}$ Berber KoOPMANs, ${ }^{1}$ Dung Ngo, ${ }^{2}$ Eddy FABer ${ }^{2}$ \\ ${ }^{1}$ NIVEL, Utrecht Universitair Medisch Centrum Groningen, Groningen
${ }^{2}$ GGZ Nederland, Amersfoort
}

In 2011 bestond het voornemen om vanaf 1 januari 2012 een eigen bijdrage in te voeren voor volwassenen die zorg in de tweedelijns GGZ ontvangen. De bedoeling hiervan was om mensen met lichte psychische problemen te ontmoedigen hulp in de gespecialiseerde GGZ te zoeken. Omdat dit voornemen veel onrust veroorzaakte onder gebruikers van tweedelijns GGZ voorzieningen, heeft GGZ Nederland in November 2011 een online enquête onder deze gebruikers gehouden. Doel was na te gaan in welke mate ze hun gebruik zouden verminderen en bij welke cliënten en binnen welke zorgcircuits dit plaats zou vinden. De gepresenteerde resultaten zijn gebaseerd op de antwoorden van 4996 respondenten. Van de respondenten geeft 70\% aan door de invoering van de eigen bijdrage het zorggebruik te gaan verminderen. Naarmate het inkomen lager is, zeggen meer cliënten af te zien van zorg. De ingeschatte ernst van de klachten en de ervaren noodzaak voor zorg is niet gerelateerd aan de geschatte zorgvermindering. De grootste vermindering is te vinden in de Jeugd-GGZ en de verslavingszorg. We concluderen dat niet degenen met lichtere problematiek de tweedelijns zorg gaan mijden, maar de mensen met de laagste inkomens, ongeacht de problematiek die ze hebben. Het voornemen tot invoering van de eigen bijdrage is na het lente-akkoord en de kabinetsformatie van Rutte-II teruggedraaid. Op grond van de gevonden resultaten is te verwachten dat een eigen bijdrage in de tweedelijns GGZ ook in de toekomst niet zal leiden tot minder oneigenlijk gebruik, maar eerder tot een verminderde toegankelijkheid van zorg voor mensen met lage inkomens.

\section{INLEIDING}

In Nederland ontvingen in 2009 al ruim 900.000 personen jaarlijks geestelijke gezondheidszorg (GGZ) in de tweedelijn.1 Deze zorg wordt verstrekt in verschillende zorgcircuits, zoals de volwassenenzorg, de Jeugd-GGZ, verslavingszorg en door vrijgevestigde psychiaters en psychologen. Omdat de 
Verhaak, P.F.M., Koopmans, B., Ngo, D., Faber, E. Eigen bijdrage in de GGZ stoot niet de mensen met lichtere problematiek maar de minder draagkrachtigen af. TSG: Tijdschrift voor

uitgaven in de GGZ de afgelopen tien jaar bleven stijgen en het gebruik van de gespecialiseerde GGZ bleef toenemen,2 is in 2011 een eigen bijdrage aangekondigd voor volwassenen die zorg in de gespecialiseerde GGZ ontvangen in het kader van de Zorgverzekeringswet.

Met een eigen bijdrage in de tweedelijnszorg dacht men een bewuster zorggebruik te stimuleren en substitutie naar de eerstelijnszorg bevorderen.

3 De verwachting was, dat mensen met lichte problemen geen gebruik meer zouden gaan maken van de gespecialiseerde GGZ.

De aankondiging van een eigen bijdrage in de tweedelijns GGZ leidde tot veel onrust, met name onder GGZ instellingen en hun cliënten. Gevreesd werd dat cliënten het belang van zorg niet altijd voldoende zouden inzien en als gevolg van de eigen bijdrage zorg zouden gaan mijden of uitstellen. Om hier een beeld van te krijgen heeft GGZ Nederland van 16 november tot en met 17 december 2011 een online enquête uitgezet onder cliënten die tweedelijns GGZ ontvangen in het kader van de Zorgverzekeringswet. Doel was om op basis van deze enquête inzicht te krijgen in de verwachtingen van cliënten in de tweedelijns GGZ over hun zorggebruik na de invoering van de eigen bijdrage van 200 euro.

Hoewel in het mei-akkoord tussen VVD, CDA, D’66, Groen Links en de Christen Unie het grootste deel van het voornemen al werd teruggetrokken en in de latere uitwerking rond de kabinetsformatie eigen bijdragen in de tweedelijns-GGZ geheel zijn verdwenen, is het illustratief om te zien hoe GGZ-cliënten aankondigden te zullen gaan reageren. Uit dit "realistische gedachtenexperiment" krijgen we antwoord op de volgende vragen: Hoe zal het zorggebruik in de tweedelijns GGZ veranderen bij verschillende hoogtes van de eigen bijdrage? . Welke cliënten (onderscheiden naar demografische kenmerken en naar ziektekenmerken) verwachten het zorggebruik te wijzigen bij een eigen bijdrage van 200 euro? . Binnen welke zorgcircuits is het percentage cliënten dat wijziging van zorggebruik verwacht bij een eigen bijdrage van 200 euro het hoogst?

\section{METHODE}

\section{Dataverzameling}

De oproep om de online enquête in te vullen is gedaan via instellingen van de leden van GGZ Nederland (dekking van ongeveer 95\% van de GGZ) en via vrijgevestigde professionals in de GGZ. Tevens is een oproep geplaatst op de site 'Meldjezorg' van het Landelijk Platform GGZ (LPGGz). Via deze intermediairs werden cliënten die op dat moment gebruik maakten van tweedelijns GGZ opgeroepen om de enquête in te vullen.

In totaal hebben 44 van de 96 instellingen positief gereageerd op het verzoek van GGZ Nederland om mee te werken aan het onderzoek, waaronder alle geïntegreerde GGZ-instellingen. De groep niet deelnemende instellingen, veelal van geringe omvang, bestond grotendeels uit instellingen waarop de geplande eigen bijdrage regeling minder van toepassing was, zoals instellingen voor beschermd wonen.

\section{De enquête}

De verwachte verandering in zorggebruik werd gemeten door de respondent bij verschillende eigen bijdragen (100, 200 of 420 euro, zie noot a) aan te laten geven of men in dat geval "'geen', ' "minder dan nu”' of "hetzelfde”' gebruik van zorg zou gaan maken. 
Verhaak, P.F.M., Koopmans, B., Ngo, D., Faber, E. Eigen bijdrage in de GGZ stoot niet de mensen met lichtere problematiek maar de minder draagkrachtigen af. TSG: Tijdschrift voor

Alle respondenten vulden vragen in over leeftijd, geslacht, de hoofddiagnose waarvoor ze in behandeling waren, de ernst van hun klachten en de ervaren noodzaak van zorg.

Daarnaast werd gevraagd of mensen bereid waren een aantal aanvullende vragen naar achtergrondkenmerken in te vullen met betrekking tot opleiding, werksituatie, samenstelling huishouden en inkomen. Alle gehanteerde antwoord categorieën zijn weergegeven in tabel 1.

Meer details over de afname van de enquête en de gemeten variabelen zijn te vinden in de rapportage die online te vinden is.3

\section{Analyse}

Om te bepalen of er verschillen zijn tussen groepen cliënten met betrekking tot verwacht zorggebruik na invoering van de eigen bijdrage van 200 euro wordt de groep die geen of minder gebruik denkt te maken van de zorg vergeleken met de groep die evenveel denkt gebruik te maken van de zorg.

Met univariate en multivariate logistische regressieanalyse is bepaald welke achtergrondkenmerken, klinische kenmerken en kenmerken van het zorgcircuit samenhangen met een verwacht verminderd zorggebruik. Per analyse werden alleen cases meegenomen die op geen der in de betreffende analyse betrokken variabelen missing values hadden.

\section{RESULTATEN}

\section{Respons}

De enquête is in totaal door 5757 personen ingevuld, waarvan 5064 (88\%) aangaven momenteel hulp te ontvangen in de tweedelijns GGZ. Respondenten die op het moment van invullen geen hulp ontvingen zijn uitgesloten van verdere analyse. Van degenen die wel hulp ontvingen, zijn er 60 vroegtijdig gestopt met het invullen van de vragenlijst en daarnaast bleken acht personen een familielid te zijn van een persoon die hulp ontvangt in de GGZ. Ook deze 68 personen zijn uitgesloten van de analyses.

De analyses betreffen daarmee 4996 personen, waarvan 84\% (4205) ook de optionele vragen over opleiding, werksituatie, samenstelling van het huishouden en besteedbaar maandinkomen heeft ingevuld.

Twee derde van de respondenten is vrouw en ruim twee derde is 25 tot 55 jaar oud. Bijna de helft van de respondenten is alleenstaand en een zelfde deel heeft geen betaald werk. De meeste respondenten (42\%) zijn middelbaar opgeleid en bijna de helft geeft aan na aftrek van alle vaste lasten een besteedbaar maandinkomen te hebben tot 500 euro.

Drie kwart van de respondenten heeft naar eigen zeggen de diagnose angststoornis, stemmingsstoornis, persoonlijkheidsstoornis of schizofrenie of een andere psychotische stoornis. Twee derde ervaart de klachten als ernstig en ongeveer $80 \%$ geeft aan dat de zorg die ontvangen wordt (zeer) noodzakelijk is voor het omgaan met problemen. Omgekeerd geeft ook ongeveer een derde aan geen tot milde klachten te ervaren en geeft bijna 20\% van de respondenten aan de zorg als niet of soms noodzakelijk te vinden.

Van de respondenten is 61\% afkomstig uit de volwassenenzorg, 26\% ontvangt zorg van een vrijgevestigde, $4 \%$ is afkomstig uit de verslavingszorg, $3 \%$ uit de jeugd GGZ, Beschermd Wonen Instelling of ouderenzorg. 
Verhaak, P.F.M., Koopmans, B., Ngo, D., Faber, E. Eigen bijdrage in de GGZ stoot niet de mensen met lichtere problematiek maar de minder draagkrachtigen af. TSG: Tijdschrift voor Gezondheidswetenschappen: 2013, 91(5), 270-275

\section{Verwacht zorggebruik bij een verschillende eigen bijdrages voor tweedelijns GGZ}

Op de vraag 'Wat doet u als de eigen bijdrage van 200 euro wordt ingevoerd?' antwoordt ongeveer $10 \%$ van de respondenten dit (nog) niet te weten. Van de respondenten die hebben aangegeven dat ze weten wat ze gaan doen als de eigen bijdrage wordt ingevoerd geeft $40 \%$ aan geen zorg meer te gaan gebruiken en $30 \%$ geeft aan minder gebruik te maken van de tweedelijns GGZ (zie Tabel 1).

Wanneer de eigen bijdrage 100 euro zou bedragen zeggen twee keer zo weinig mensen geen zorg meer te gebruiken dan bij een eigen bijdrage van 200 euro terwijl het percentage mensen dat minder gebruik denkt te gaan maken van $26 \%$ naar $30 \%$ gaat. Bij een eigen bijdrage van 420 euro geeft $72 \%$ aan geen gebruik meer te maken van zorg en $15 \%$ denkt minder gebruik te maken van de zorg. Slechts 13\% denkt bij een eigen bijdrage van 420 euro nog steeds evenveel gebruik te blijven maken van de zorg.

\section{Welke cliënten verwachten het zorggebruik te wijzigen?}

Tabel 2 geeft de achtergrondkenmerken van de ondervraagde cliënten weer, uitgesplitst naar cliënten die zeggen geen of minder gebruik van de GGZ te gaan maken en cliënten die zeggen dat ze evenveel gebruik van de GGZ zullen blijven maken bij een hypothetische eigen bijdrage van 200 euro.

Het verschil tussen leeftijdsgroepen is getoetst met Anova en gespecificeerd met de Bonferoni-toets. De jongste cliëntengroep geeft significant vaker aan (78\%) dat ze hun zorg zullen gaan minderen bij een eigen bijdrage van 200 euro, dan de leeftijdsgroepen 25-44 jaar en 55 jaar en ouder. Tussen andere leeftijdsgroepen zijn geen significante verschillen. Ook respondenten die inwonen bij hun ouders, laag opgeleiden en respondenten met een laag inkomen geven relatief vaak aan hun zorg te zullen gaan minderen.

Mensen met schizofrenie of een andere psychotische stoornis zijn het minst geneigd aan te geven geen of minder zorg te gaan gebruiken. Ten opzichte van deze groep geven mensen met een angststoornis, stemmingsstoornis, persoonlijkheidsstoornis of overige stoornis vaker aan hun zorggebruik te gaan verminderen. Mensen met verslavingsproblematiek doen dat het meest. Er zijn geen verschillen in aangegeven zorggebruik op basis van gepercipieerde ernst van de klachten of noodzaak van de zorg. Mensen die hun klachten als zeer ernstig of de zorg als zeer noodzakelijk ervaren geven niet minder vaak aan om bij een eigen bijdrage van 200 euro zorg te gaan minderen dan mensen die hun klachten als mild bestempelen of de zorg niet noodzakelijk vinden.

Cliënten van vrijgevestigde psychologen of psychiaters geven het minst vaak aan hun zorggebruik te gaan verminderen.

Cliënten uit de Jeugd-GGZ en de verslavingszorg doen dat het meest.

\section{Kenmerken van mensen die aangeven geen of minder gebruik te maken van zorg bij een eigen bijdrage van 200 euro}

Tabel 3 drukt de samenhang tussen cliënt kenmerken en het voornemen om minder zorg te gaan gebruiken uit in odds ratio's, waarbij voor andere kenmerken gecontroleerd wordt (multivariaat model). De kenmerken leeftijd, werksituatie en zorgcircuit, die univariaat samenhingen met het voornemen om minder zorg te gaan gebruiken, waren in het multivariaat model niet significant. Het model in tabel 3 is opnieuw gedraaid met uitsluitend de significant bijdragende variabelen. 
Verhaak, P.F.M., Koopmans, B., Ngo, D., Faber, E. Eigen bijdrage in de GGZ stoot niet de mensen met lichtere problematiek maar de minder draagkrachtigen af. TSG: Tijdschrift voor

Gecorrigeerd voor de andere clip kenmerken gaven mensen met een besteedbaar maandinkomen van 0 tot 500 euro bijna vier keer zo vaak aan geen of minder zorg te gaan gebruiken dan mensen met een besteedbaar maandinkomen van meer dan 2000 euro. Ook mensen met een besteedbaar maandinkomen tussen de 500 en 2000 euro gaven vaker aan geen of minder zorg te gaan gebruiken dan mensen met een besteedbaar maandinkomen van meer dan 2000 euro. Laag opgeleiden geven daarnaast drie keer zo vaak aan geen of minder gebruik te gaan maken van de zorg dan mensen met een hoge opleiding.

Ook mensen die samenwonen of gehuwd zijn en kinderen hebben, zeggen ongeveer anderhalf keer zo vaak dan mensen die samenwonen of gehuwd zijn en geen kinderen hebben dat ze geen of minder zorg gaan gebruiken.

Mensen met schizofrenie en andere psychotische stoornissen geven minder dan mensen met andere stoornissen aan dat ze hun zorggebruik gaan minderen. Het meest wordt dit aangegeven door mensen met verslavingsstoornissen.

\section{DISCUSSIE}

Met deze enquête wilde GGZ-Nederland nagaan hoe de cliënten van de GGZinstellingen zouden reageren op de eigen bijdrage regeling. Van de GGZ cliënten die deelgenomen hebben aan de enquête geeft $70 \%$ aan door de hypothetische invoering van de eigen bijdrage van 200 euro het zorggebruik te gaan verminderen; $40 \%$ geeft aan geen en 30\% geeft aan minder gebruik te maken van de tweedelijns GGZ.

\section{[TABEL 1] [TABEL 2]}

Cliënten laten zich vooral leiden door hun inkomenssituatie. De ingeschatte ernst van de klachten en de ervaren noodzaak voor zorg is niet gerelateerd aan de inschatting dat men zorggebruik al dan niet zal minderen. In dit opzicht zou de maatregel niet het gestelde doel bereiken om de zelfgerapporteerde lichtere problematiek buiten de tweedelijns GGZ te houden.

De cliënten die aangeven het zorggebruik te zullen gaan verminderen na de invoering van de eigen bijdrage zijn vooral te vinden in de Jeugd-GGZ en de verslavingszorg en hebben met name verslavingsproblematiek of, echter minder vaak, een angst-, stemmings- of persoonlijkheidsstoornis.

We nemen aan dat mensen met hogere inkomens vaker naar een vrijgevestigd psycholoog of psychiater gaan en daar is het aantal cliënten dat aangeeft het zorggebruik te zullen verminderen dan ook het laagst.

Deze conclusies zijn gebaseerd op de respons van ongeveer 5000 cliënten. Een dergelijke steekproefomvang leidt tot robuuste resultaten. Met betrekking tot de representativiteit van de ondervraagde cliënten kunnen we stellen dat, vergeleken met de GGZ populatie (zie noot b) in de verschillende instellingen vrouwen onder de respondenten van deze enquête zijn oververtegenwoordigd (68\% ten opzichte van $54 \%$ in de GGZ). De leeftijdsopbouw, verdeling over de zorginstellingen en de verdeling in diagnose categorieën komen redelijk overeen met de GGZ populatie in de instellingen (exclusief de vrijgevestigde psychologen en psychiaters). 
Verhaak, P.F.M., Koopmans, B., Ngo, D., Faber, E. Eigen bijdrage in de GGZ stoot niet de mensen met lichtere problematiek maar de minder draagkrachtigen af. TSG: Tijdschrift voor

\section{[TABEL 3]}

Het aantal 65+-ers en daarmee het aantal cliënten uit de ouderenzorg is ondervertegenwoordigd ( $5 \%$ ten opzichte van 14\%) en het aantal cliënten uit de volwassenenzorg is oververtegenwoordigd.

Gegeven de opzet van de studie is niet bekend wat de duur van de stoornis en de objectieve zorgzwaarte van de respondenten was. Wel zijn zowel cliënten die hun stoornis zeer ernstig en de zorg absoluut noodzakelijk inschatten als cliënten die hun stoornis lichter inschatten vertegenwoordigd. Maar het algemene oordeel dat men zorg zal gaan minderen, signaleren we bij een forse meerderheid van vrijwel iedere subcategorie. Daarom achten we de uitkomst representatief voor de mening van de GGZ-cliënten die eind 2011 bij een GGZ instelling onder behandeling waren. In de enquête is gevraagd naar de intentie van cliënten om het zorggebruik te veranderen. Dit hoeft niet overeen te komen met het daadwerkelijk stoppen of minderen van het zorggebruik. De emoties die dit onderwerp met zich meebrengt en de uitnodiging voor deelname aan de enquête door de instellingen zelf, de wervingstekst en de niet geheel neutraal geformuleerde link van de website 'recht op GGZ' kunnen bijgedragen hebben aan een overschatting van het aantal zorgverminderaars.

Deze zelfrapportage is ook een beperkende, maar op deze schaal onoverkomelijke, factor als het gaat om bijvoorbeeld de diagnose, de ervaren ernst van de klachten en noodzaak van zorg of het besteedbaar inkomen. Deze gegevens representeren in dit geval een subjectief oordeel van de cliënt en niet een klinisch oordeel. Dit subjectieve oordeel is echter wel datgene wat een cliënt meeneemt in de besluitvorming.

De uitkomst dat de meeste ondervraagde cliënten zeggen de zorg te zullen gaan minderen, is in die zin opvallend dat in recent panelonderzoek onder gezonde mensen maar 5\% zegt daadwerkelijk minder medische zorg gebruikt te hebben doordat een deel van de kosten voor eigen rekening kwam.5 Er is eerder getracht om uitgaven in de zorg te temperen door eigen bijdragen te heffen of een eigen risico in te voeren. Na invoering van een algemene eigen bijdrage voor toenmalig ziekenfonds verzekerden, bleken de uitgaven van de zorg met $5 \%$ te stijgen, nadat de maximum eigen bijdrage was betaald. Bij invoering van eigen bijdragen voor medicijnen (de “'medicijnknaak”), trad zo'n effect niet op. Een eigen risico leidt niet tot meer zorgvermindering dan een eigen bijdrage. 6 Van de eigen bijdrage maatregel die in 1997 voor de Nederlandse ziekenfondsverzekerden werd ingevoerd, kon op voorhand al weinig effect verwacht worden, omdat deze vooral gericht was op vervolgconsumptie, waarop de verzekerde relatief weinig invloed heeft.6 Hoewel deze maatregel al snel weer werd ingetrokken en weinig onbedoelde neveneffecten heeft gehad, heeft ze wel onrust teweeg gebracht bij sommige verzekerden.7

\section{ALGEMENE CONCLUSIE}

Van een eigen bijdrage in de tweedelijns GGZ is op dit moment geen sprake meer. Het is echter goed om vast te stellen dat wanneer dat in de toekomst weer overwogen wordt, het niet degenen met lichtere problematiek zullen zijn die de tweedelijns zorg gaan mijden, maar de mensen met de laagste inkomens, ongeacht de problematiek die ze hebben en ongeacht hoe hard ze denken die zorg nodig te hebben. De maatregel zal zodoende waarschijnlijk niet bijdragen tot een gewenste sturing van 
Verhaak, P.F.M., Koopmans, B., Ngo, D., Faber, E. Eigen bijdrage in de GGZ stoot niet de mensen met lichtere problematiek maar de minder draagkrachtigen af. TSG: Tijdschrift voo Gezondheidswetenschappen: 2013, 91(5), 270-275

lichtere problematiek van tweede naar eerste lijn, maar hooguit een bijdrage leveren aan de financiering van de zorgkosten.

De minst draagkrachtige GGZ-cliënten geven aan minder of geen zorg te zullen gaan gebruiken, waarmee het solidariteitsprincipe in de zorg ondermijnd kan worden.

\title{
NOTEN
}

a Het bedrag van 420 euro kwam voort uit het idee dat men naast een eigen GGZbijdrage van 200 euro ook met een generieke eigen bijdrage aan ziektekosten, die in 2011220 euro bedroeg, rekening moest houden.

b Referentiegegevens met betrekking tot de populatie per 1 mei 2010 werden verstrekt door GGZ-Nederland.

\begin{abstract}
Own contribution in costs for mental health care will not exclude clients with minor mental problems but leads to a decrease of clients with the lowest income In 2011 an own contribution in costs for specialized mental health care was considered by health authorities. This was meant to exclude clients with minor mental problems from specialized mental health care. The branch organization of mental health care in the Netherlands (Dutch Association of Mental Health and Addiction Care) has held an online survey among clients in specialized care in November 2011.

With this survey the Association intended to estimate intentions to lower the use of specialized mental health care.

Results are based on 4996 completed surveys. 70\% of the respondents reported an intention to lower their use of care facilities as a result of the own contribution in costs. The intention to abstain from future care was directly related to the income situation. Perceived seriousness of illness and perceived necessity of care was not related to the intention of care decrease. The largest expected decrease in care was found in youth mental health care and addiction care. We conclude that the measure (that has not been effectuated) would not have led to a decrease of clients with the least serious mental health problems but to a decrease of clients with the lowest income, whatever their problems are.
\end{abstract}

\section{LITERATUUR}

1. Dijk S van, Knispel A, Nuijen J. GGZ in tabellen. Utrecht: Trimbosinstituut, 2011.

2. http://www.rijksoverheid.nl/ministeries/vws/nieuws/2011/07/ 26/eigen-bijdrage-ggzverlaagd.html 3. Ministerie van VWS. Kamerbrief monitor eigen bijdrage GGZ. Den Haag: Ministerie van VWS, 27-02-2012

4. Koopmans B, Verhaak P. Verwacht zorggebruik als gevolg van de eigen bijdrage in de tweedelijns GGZ. Utrecht: NIVEL, 2012. www.nivel.nl/publicaties

5. Maat MJP, Jong JD de. Eigen risico in de zorgverzekering: het verzekerden perspectief. Een onderzoek op basis van het Consumenten Panel Gezondheidszorg. Utrecht: NIVEL, 2010.

6. Kerssens JJ, Delnoij DMJ. Effecten van de eigen betaling in de gezondheidszorg. Utrecht: NIVEL, 2000.

7. Delnoij DMJ, Hutten JBF, Ros CC et al. Effecten van eigen bijdragen in het ziekenfonds in Nederland. Tijdschr Gezondheidswet 1999;77:406-12. 
Verhaak, P.F.M., Koopmans, B., Ngo, D., Faber, E. Eigen bijdrage in de GGZ stoot niet de mensen met lichtere problematiek maar de minder draagkrachtigen af. TSG: Tijdschrift voo Gezondheidswetenschappen: 2013, 91(5), 270-275

8. Ministerie van WWS. Eigen betalingen in perspectief. Beschrijving van de theorie achter eigen betalingen en de praktijk in België" en Frankrijk. Den Haag: Ministerie van VWS, 2002.

\section{TABELLEN EN FIGUREN}

Tabel 1 Door cliênten verwacht eigen zorggebruk bij eigen bijdrage van 200 euro \#

\begin{tabular}{|c|c|c|c|}
\hline Wat doet $u$ als... & $\begin{array}{l}U \text { zelf } 100 \text { euro per jaar moet } \\
\text { betalen voor uw zarg } \\
(n=4299)\end{array}$ & $\begin{array}{l}U \text { zelf } 200 \text { euro per jaar moet } \\
\text { betalen voor uw zorg? } \\
(n=427)\end{array}$ & $\begin{array}{l}U \text { zelf } 420 \text { euro per laar moet } \\
\text { betalen woor uw zorg? } \\
(\mathrm{n}=4211)\end{array}$ \\
\hline $\begin{array}{l}\text { Ik maak dan geen gebruik meer van de } G G Z \text { (\%) } \\
\text { Ik maak dan mind er gebruik wan de } G G Z \text { (\%g) }\end{array}$ & $\begin{array}{r}855(20 \% 9) \\
1134(26 \%)\end{array}$ & $\begin{array}{l}1713(40 \%) \\
1266(30 \%)\end{array}$ & $\begin{array}{r}3050(72 \%) \\
623(15 \%)\end{array}$ \\
\hline Ik maak dan everneel gebruik van de GGZ (\%) & $2310(54 \%)$ & $1298(30 \%)$ & $538(13 \%)$ \\
\hline
\end{tabular}

\# Van alle respondenten heeft respectievelijk $11 \%, 11 \%$ en $13 \%$ aangegeven niet te weten of hil/zilj geen, minder of everveel zorg denkt te gaan gebruiken bil een eigen bijdrage van 100, 200 en 420 euro. De percentages de worden genoemd in de tabel betreffen de groep die wel heeft aangegeven wat ze gaan doen. 
Verhaak, P.F.M., Koopmans, B., Ngo, D., Faber, E. Eigen bijdrage in de GGZ stoot niet de mensen met lichtere problematiek maar de minder draagkrachtigen af. TSG: Tijdschrift voor Gezondheidswetenschappen: 2013, 91(5), 270-275

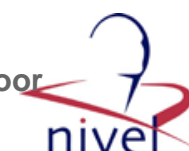

Tabel 2 Achtergrondkenmerken van ciënten, uitgesplitst naar het percentage dat minder gebruik zal maken en het percentage dat gelijk gebruik van de GGZ zal bijiven maken bilj een eigen bijdrage van 200 euro.

\begin{tabular}{|c|c|c|c|c|c|c|}
\hline \multirow[t]{2}{*}{ Kenmerk } & \multirow[t]{2}{*}{ Waarde } & \multicolumn{2}{|c|}{ Minder gebrulk } & \multicolumn{2}{|c|}{ Gelijk Gebruik } & \multirow[t]{2}{*}{ Toets } \\
\hline & & N & $\%$ & N & $\%$ & \\
\hline \multirow[t]{2}{*}{ Geslacht } & Man & 957 & $69 f 6$ & 428 & $31 \%$ & $x^{2}-0,30 ;$ n.s. \\
\hline & Vrouw & 2022 & $70 \% 6$ & 870 & $30 \%$ & \\
\hline \multirow[t]{6}{*}{ Leeftlijd } & $1 B-24$ & 364 & $78 \%$ & 105 & $22 \%$ & $F=4,12 ; p=0,0001$ \\
\hline & $25-34$ & 619 & $69 \%$ & $2 B 4$ & $31 \%$ & \\
\hline & $35-44$ & 647 & $69 f 6$ & 296 & $31 \%$ & \\
\hline & $45-54$ & 800 & $71 \%$ & 334 & $29 \%$ & \\
\hline & $55 \cdot 64$ & 423 & $67 \%$ & 208 & $33 \%$ & \\
\hline & $65+$ & 126 & $64 \%$ & 71 & $36 \%$ & \\
\hline \multirow[t]{4}{*}{ Woons ituatle } & Alleenstaand & 1136 & $68 \%$ & 541 & $32 \%$ & $\begin{array}{l}X^{2}=12,45 \\
p=0,006\end{array}$ \\
\hline & Inwonend & 273 & $74 \%$ & 96 & $26 \%$ & \\
\hline & Samenwonend/gehuwd zonder kind. & 487 & $64 \%$ & 269 & $36 \%$ & \\
\hline & Samenwonend/gehuwd met kinderen & 608 & $70 \%$ & 258 & $30 \%$ & \\
\hline \multirow[t]{3}{*}{ Opleiding } & Laag & $77^{8}$ & 8076 & 191 & $20 \%$ & $\begin{array}{l}X^{2}=149.78 \\
p<0,001\end{array}$ \\
\hline & Middelbaar & 1123 & $70 \% 6$ & 471 & $30 \%$ & \\
\hline & Hoog & 672 & $56 \%$ & 525 & $44 \%$ & \\
\hline \multirow[t]{3}{*}{ Werksituatle } & Betaald werk & 636 & $64 \%$ & 359 & $36 \%$ & $\begin{array}{l}X^{2}=12,68 \\
P=0,002\end{array}$ \\
\hline & Deels betaald werk (tijdelljk arbeidsongeschilkt & 688 & $70 \%$ & 297 & $30 \%$ & \\
\hline & Geen betald werk & 1193 & $70 \%$ & 507 & $30 \%$ & \\
\hline \multirow[t]{4}{*}{ Maandinkomen ${ }^{a, b}$} & $0-500$ euro & 1064 & $75 \%$ & 361 & $25 \%$ & $\begin{array}{l}X^{2}=143.82 \\
p=0.001\end{array}$ \\
\hline & $500-1000$ euro & 542 & $71 \%$ & 220 & $29 \%$ & \\
\hline & $1000-2000$ euro & 446 & $66 \%$ & 227 & $33 \%$ & \\
\hline & $>2000$ euro & 156 & $43 \%$ & 211 & $57 \%$ & \\
\hline \multirow[t]{8}{*}{ Stoornissen } & Stemm ings stoor nis & 830 & $71 \%$ & 346 & $29 \%$ & $\begin{array}{l}X^{2}=64,61 \\
p=0,000\end{array}$ \\
\hline & Persoonlijkheidss toornis & 557 & $69 \%$ & 247 & $31 \%$ & \\
\hline & Angsts toornis & 399 & $72 \%$ & 157 & $28 \%$ & \\
\hline & Schlzofrenie of andere psychotische stoornis & 216 & 6076 & 142 & $40 \%$ & \\
\hline & Ontwikkelingsstoornis & 162 & $67 \%$ & 80 & $33 \%$ & \\
\hline & Verslavingspr oblemen & 104 & $85 \%$ & $1 B$ & $15 \%$ & \\
\hline & Overige stoornissen & 274 & $71 \%$ & 114 & $29 \%$ & \\
\hline & Meerdere stoornissen tegelijk & 138 & $68 \%$ & 64 & $32 \%$ & \\
\hline \multirow[t]{3}{*}{ Ernst klachten } & Ik ervaar geen klachten & 72 & $64 \%$ & 40 & $36 \%$ & $\mathrm{X}^{2}-2,52 ;$ in.s. \\
\hline & ik heb milde klachten & 944 & $69 \%$ & 428 & $31 \%$ & \\
\hline & Ik heb ernstige klachten & 1963 & $70 \% 6$ & 830 & $30 \%$ & \\
\hline Noodzaak & niet noodzakelijk & 46 & $73 \%$ & 17 & $27 \%$ & $X^{2}=0,42 ;$ n.s. \\
\hline \multirow[t]{3}{*}{ behandling } & soms noodzakelijk & 472 & $69 f 6$ & 209 & $31 \%$ & \\
\hline & noodzakelijk & 1237 & $69 \%$ & 543 & $31 \%$ & \\
\hline & zeer noodzakelijk & 1224 & 7076 & 529 & $30 \%$ & \\
\hline \multirow[t]{6}{*}{ Zorgcircult } & Volwassenenzorg & 1732 & $70 \% 6$ & 757 & $30 \%$ & $\begin{array}{l}X^{2}=38,93 \\
p=0,000\end{array}$ \\
\hline & Vrilgevestigd psycholoog of psychiater & 697 & $65 \%$ & 379 & $35 \%$ & \\
\hline & Verslavingszorg & 122 & $81 \%$ & 29 & $18 \%$ & \\
\hline & Jeugd-GGZ & 100 & $78 \%$ & 28 & $22 \%$ & \\
\hline & Beschermd of begeleid wonen & 89 & $72 \%$ & 35 & $28 \%$ & \\
\hline & Ouderenzorg & 82 & $70 \% 6$ & 35 & $30 \%$ & \\
\hline
\end{tabular}

"Besteedbaar maandinkomen huishouden: inkomen na aftrek van alle vaste lasten

b Van al le respondenten heeft $13 \%$ aangegeven het besteedbaar maandinkomen niet te weten of niet te willen zeggen. De percentages die in de tabel worden genoemd betreffen de groep die het besteedbaar inkomen wel heeft aangegeven 
Verhaak, P.F.M., Koopmans, B., Ngo, D., Faber, E. Eigen bijdrage in de GGZ stoot niet de mensen met lichtere problematiek maar de minder draagkrachtigen af. TSG: Tijdschrift voor Gezondheidswetenschappen: 2013, 91(5), 270-275

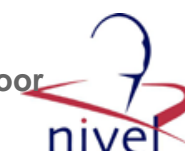

Tabel 3 Relatie tussen significante achtergrond- en klinische kenmerken en de kans dat diërten hun zorggebuik te gaan verminderen

\begin{tabular}{|c|c|c|}
\hline & $\begin{array}{l}\text { Multivarlaat model: } \\
\text { Achtergon okenmerken (OR) }\end{array}$ & $95 \%$-betrouwbaarheidsinterval \\
\hline \multicolumn{3}{|l|}{ Woonsituatie } \\
\hline Alleenstaand & 0,88 & Q,70-1,10 \\
\hline Inwonend & 0,96 & Q.68-1,35 \\
\hline Samenwonend/gehuwd zonder kinderen (ref) & $1, \infty$ & \\
\hline Samenwonend/gehuwd met kinderen & $1,46^{*}$ & $1,12-1,90$ \\
\hline \multicolumn{3}{|l|}{ Opleiding } \\
\hline Laag & $3,08^{*}$ & $2,42-3,91$ \\
\hline Middel baar & $1,66^{*}$ & $1,38-2,01$ \\
\hline Hoog (ref) & $1, \infty$ & \\
\hline \multicolumn{3}{|l|}{ Besteedbar maand-inkomen huishouden \# } \\
\hline $0-500$ euro & $3.93^{*}$ & $2,92-5,29$ \\
\hline $500-1000$ euro & $3.44^{*}$ & $2,52-4,69$ \\
\hline $1000-2000$ euro & $2,56^{*}$ & $1,90-3,46$ \\
\hline$>2000$ euro (ref) & $1, \infty$ & \\
\hline \multicolumn{3}{|l|}{ Stoomis } \\
\hline Angststoornis & $2,1^{*}$ & $1,49-2,97$ \\
\hline Stemmingsstoornis & $2,05^{*}$ & $1,51-2,7^{8}$ \\
\hline Persoonlijkheidsstoornis & $1,79^{*}$ & $1,31-2,44$ \\
\hline Schlzofrenie of andere psychotische stoornis (ref) & $1, \infty$ & \\
\hline Ontwikkel ingsstoornis & $1,67^{*}$ & $1,10-2,5^{2}$ \\
\hline Verslavingsproblemen & $3.5^{8 *}$ & $1,95-6,57$ \\
\hline Overige stoornissen & $2,14^{*}$ & $1,47-3,10$ \\
\hline Meerdere stoomissen tegelijk & $1,70^{*}$ & $1,11-2,59$ \\
\hline
\end{tabular}

$* \mathrm{p}<0,05$

OR: odds ratio

\#: Besteedbaar maandinkomen hulshouden: inkomen na aftrek van alle vas te lasten 